\title{
Impact of Saudi Digital Library (SDL) to Saudi Research Output: A Review
}

\author{
William Taala ${ }^{*}$, Filoteo B. Franco Jr. ${ }^{2}$, Rino S. De Sagun ${ }^{1}$ \\ ${ }^{1}$ Fakeeh College for Medical Sciences, Jeddah, KSA \\ ${ }^{2}$ Prince Mohammad Bin Salman College for Business and Entrepreneurship, Jeddah, KSA \\ Email: *wtaala@fcms.edu.sa,ffranco@mbsc.edu.sa, rsdesagun@fcms.edu.sa
}

How to cite this paper: Taala, W., Franco Jr., F.B. and De Sagun, R.S. (2019) Impact of Saudi Digital Library (SDL) to Saudi Research Output: A Review. Open Access Library Journal, 6: e5331. https://doi.org/10.4236/oalib.1105331

Received: March 12, 2019

Accepted: March 18, 2019

Published: March 21, 2019

Copyright (C) 2019 by author(s) and Open Access Library Inc.

This work is licensed under the Creative Commons Attribution International License (CC BY 4.0).

http://creativecommons.org/licenses/by/4.0/

Open Access

\begin{abstract}
A paper that has hypothetically illustrated the need for the digital libraries in modern learning environments primarily because of their reach effectiveness in the dwindling physical space available. In essence, the utilization of digital libraries in Saudi Arabia has opened more room for research thus ensuring that students are properly informed while compiling academic content. It further focused on the positive impacts as well as the negative to illustrate the needs to further improve the said digital space. To date the Saudi Digital Library fondly called to locals as SDL has revolutionized researching inside the kingdom making it at par with other first world countries in spite of late coming.
\end{abstract}

\section{Subject Areas}

Library, Intelligence and Philology

\section{Keywords}

Saudi Digital Library, Digital Library, Digital Research

\section{Introduction}

The quest for knowledge has amplified the need for the introduction of digital libraries cognizant of the high costs of publishing and increased uptake of technology as well as inadequate physical libraries. Fundamentally, institutions of learning are resulting in electronic learning strategies to tap into the emerging need for research and access to education.

Global advancement of information and communication technology has sprung access to information beyond the confines of the physical libraries primarily as a result of decreased acreage to construct libraries compounded by the 
need to stretch resources far and wide. Libraries, in essence, are regarded as the distributors and custodians of knowledge in their capacity to store books, journals, and maps among other materials used in the learning process.

For this reason, the digital library implies the provision of information using digital platforms such as electronic books and newspapers among others. The quest to access information in books is dwindling at an alarming with the need for published literature surpassing the available copies. In light of this, only a handful of persons get an opportunity to read the available literature.

However, the introduction of digital libraries has in the recent past attracted scholarly excellence as more people turn to digital libraries to access literature. For example, through the digital library, groups of people may read the book at diverse access points globally. Interestingly, digital libraries have smoothened access to literature in learning institutions thus promoting research.

This literature review argues that the Saudi Digital Library has significantly contributed to the research output of Saudi Arabia by broadening the physical libraries that were threatened by reduced space, although inadequate infrastructural development to tap into the technological practice is a challenge that the country's education sector continues to grapple with.

\section{Saudi Digital Library}

Aware of the impact of the higher education institutions in the provision of quality human resource for the domestic and foreign markets, ministries of education in the Arab countries have embarked on the digitization of the libraries that will play pivotal roles in the provision of quality academic and research data. With approximately 21 government-funded universities and 11 private universities in Saudi Arabia, it is evident that the country requires sufficient libraries to serve the growing student population (Alasem, 2013) [1].

Additionally, the Saudi Digital Library commonly abbreviated as SDL was established in 2010 to open up more opportunities to access literature. The library has approximately 240,000 full electronic books covering multiple fields of study subscribing to multiple local, regional and international publishers for content (Alasem, 2013) [1]. The establishment of the digital library is meant to ease the research process for not only the student but also faculty staff and researchers in Saudi Arabia.

Ideally, the proliferation of web-based technologies has potentially helped in the collection of available data. Partnering with reputable publishers such as and not limited to Oxford University Press, Harvard University, Taylor and Francis, Springer and Elsevier, the Saudi Digital Library infrastructure project is strategically positioned to ensure ease of access to quality data that is important in the compilation of research material. For example, partnering with credible publishers optimizes service delivery and quality of data.

Additionally, the Saudi Digital Library is among the largest gathering of electronic books in the Arab region opening up opportunities for the Saudi Arabian 
population to competitively achieve academic and research excellence with colleagues across the globe. Through this initiative, for example, a student based in Saudi Arabia is aware that the information he/she uses in the classroom is identical to one utilized in the United States cognizant of the uniformity in access and interpretation of data from publishers (Alasem, 2013) [1].

\section{Impact of the Saudi Digital Library}

\section{1) Positive Impacts: winning regional recognition}

Since its' launch in 2010, the Saudi Digital Library has transformed the e-learning platform in the Arabic region winning accolades along the way from publishers and the sector strategists. According to Baker (2011) [2], the Saudi Digital Library won the Arab Federation for Libraries and Information award for its distinguished projects aligned towards informative digital references according to alarabiyah newspapers [3].

2) Positive Impacts: increased technological concentration in the education sector

Before the introduction of the Saudi Digital Library, only a handful of institutions of higher learning had resulted in the use of e-learning initiatives. However, the introduction of the digital research platform has transformed the quest and need for technological information development in the Arabic country. In this regard, the government through the relevant ministries is channeling huge budgetary allocations to the adoption of information technology at the basic elementary studies in an attempt to equip learners with the prerequisite skills to operate technological devices as well as aligning the country towards internet connectivity (Al-Maini, 2013) [3].

The Saudi government allocates lions' share of the budget to educational technology in the country. This is meant to promote the integration of technology in the learning process such that a larger portion of learners get access to education. Interestingly, the adoption of the Saudi Digital Library concept has amplified the country as the beacon of human resource investment. With oil as the primary economic backbone, education is swiftly ranking among the pacesetters of the Arabian economy through provision of quality human resource (Al-Maini, 2013) [4].

According to Simsim (2011) [5], internet usage of education purposes is on a gradual increase in Saudi Arabia with a study conducted by the King Saud University illustrating that approximately 49.3 percent of persons who use the internet do so purposely for education. This portrays the need for emphatic internet connectivity roll out in the country in an attempt to improve internet access to students. The introduction of the Saudi Digital Library has positively changed internet access costs by telecommunication companies in the region. This is meant to promote continuous utilization of the digital platform by students who are at times not financially stable to sustain internet connectivity.

3) Positive Impacts: improvement in Research and an infinite number of resources 
With education being a critical pillar in Saudi Arabia's social, economic growth, the government allocates approximately a quarter of its budget to education spending around the United States $\$ 53.9$ billion in 2014 and US\$55.5 billion in 2015. This illustrates the emphasis placed on education to sustain the economy through the provision of highly skilled human resource in a dynamic global environment (Al-Maini, 2013) [4].

Interestingly, the high number of universities opened up in the Arabic country in the recent past has illustrated the need for adoption of electronic learning platforms to sustain the competitive advantage in comparison to other universities globally. Introduction of the electronic learning platforms in Saudi Arabian universities is projected to reach out to students spread far and wide across the country who constantly face exclusion from accessing physical libraries. This gave birth to the Saudi Digital Library concept a decade ago.

For this reason, the introduction of the Saudi Digital Library is meant to scale up the research ability of students and faculty members alike through simplified access to quality, timely and sufficient research in all academic disciplines. Before the introduction of the Saudi Digital Library, the academic fraternity had insufficient access to literature to supplement their research, but with the inclusion of the digitized library, it is poised to change the quality of research in the Arab country.

The Saudi Arabia education fragmentation has seen universities open up satellite campuses in remote areas in the quest to ensure that every citizen has the opportunity to access education. To this effect, the Saudi Digital Library has opened up chances for electronic learning platforms for individuals across the country cognizant of the conclusion that the universities present are unable to accommodate all students physically.

In light of this, the digital library assists those seeking electronic learning alternatives with significant academic literature to spruce up their work engagements. In the context of research, the digital library in Saudi in partnership with credible publishers helps students access information that is timely thus creating a level ground with compatriots in other parts of the world.

Additionally, digital libraries are not limited to obstacles such as time. In this regard, the introduction of the Saudi Digital Library project helped in multiplying access to information far and wide against a backdrop of challenges such as time limitation associated with physical libraries. To this end, it is evident that the digitized information sources help improve the quality of research.

Interestingly, space is limited regarding physical access to books, but with digitized library services, individuals accessing these services are offered an opportunity to expound on their research capacity. For example, rolling out published books online helps to reach out to multiple persons (Adeyinka and Kwanya, 2018) [6].

According to Adeyinka and Kwanya (2018) [6], digitization of library services has given hope to researchers to continue offering additional research material with consumption of these data increasing each day cognizant of the prolifera- 
tion of digital access across the world. For example, a student in the rural area can access information on the digital platform thus scaling down the expenditure associated with rural-urban migration.

Furthermore, continued use of the internet as the ideal avenue for data collection has watered down the impact of credible information sources necessary for academia. For this reason, the introduction of the Saudi Digital Library platform has opened up room for credibility analysis of data thus improving the quality of research for students and members of the faculty.

Through the digital platform, publishers limit the production of substandard literature in the market. For example, a student who uses the digital platform to search for data is likely to generate quality work compared to one that either sought information online or just visited a library with no accreditation. Interestingly, students are unaware of the best libraries to seek knowledge but through such initiatives as the Saudi Digital Library harmonization of information aid in the provision of standardized data.

Use of the Saudi Digital Library has lessened the proliferation of poor quality data for students that may injure their scholarly goals. Fundamentally, the harmonization of the data collection point in Saudi Arabia ensures that the concerned parties are quick to point out any errors unlike in physical libraries where filtration of unnecessary information is at times impossible.

The Saudi Digital Library provides a platform for students and faculty members alike to upload their research projects in an attempt to attract critical analysis from other academic scholars across the world. In this regard, this is positioned to help improve the ranking of Saudi's universities on the global map, therefore, perpetuating academic tourism in the Arab nation. For instance, a student in Africa may opt to pursue his/her studies in a Saudi Arabian institution of higher learning primarily because of the platform offered by the digital library as well as the provision of multiple research material in comparison to the state of higher learning in his/her own country.

Availability of an infinite number of resources from the Saudi Digital Library aims at empowering the state of research in the Arabian country. Interestingly, a significant number of persons in the country's institutions of higher learning get an opportunity to improve their research quality by accessing multiple research material.

Additionally, the Saudi Digital Library represents a modern technological reserve of knowledge. This implies that the content available online through the digital libraries is not vulnerable to damage as compared to the physical libraries whose durability is constrained by physical space. In light of this, the digital libraries in the wake of technological growth are likely to last longer and help multiple persons in the future. It is easier to access recent and past research articles compared to physical libraries. With a click of a button, a learner or faculty member has the opportunity to select from a wide range of documents.

Publishers across the world were faced numerous challenges including and not limited to access to institutions of higher learning faculty members and stu- 
dents. However, the introduction of the Saudi digital library in 2010 has transformed these challenges to success stories. Interestingly, access to literature from the publishers has in the recent past scaled the heights of international boundaries with students able to access the literature from their universities. This link with the Saudi digital library has paved the way for publishing companies to produce more literature as the consumption trends increase (Baker, 2011) [3].

Furthermore, in as much as the digital library in Saudi Arabia led to the untimely termination of jobs for librarians in physical libraries, the introduction of this practice in the institutions of higher learning opened up new opportunities for information technology experts in the country. The introduction of the Saudi Arabian Digital Library was timely precisely because the parallel beginning of online government services.

Besides, the Saudi Digital Library has a positive impact on the accessibility of information for research purposes. In light of this, the digital platform aligns the user not only as a passive consumer of information but also a major contribution of the same. Fundamentally, by giving users the opportunity to upload their content for consumption by other library users, it provides a scenario where users become the very own critics of their ideologies. For example, a faculty member is at liberty to upload his/her research article in the digital platform, therefore, becoming actively involved in the promotion of intellectual material.

In essence, physical libraries only position users as active or passive consumers of information thus the timely need of the digital platform. To this end, the active participation of users in the provision of data helps in improving the state of research in Saudi Arabia. The scarcity of data, for instance, because of limited physical space works against the contribution to research content for researchers thus the pivotal role of digital libraries.

4) Positive Impacts: affordability and strengthening intellectual property

Education is a priceless commodity that helps in the social, economic and political development of a country precisely based on the perception that it provides the much-need expertise and knowledge. To this effect, lack of adequate resources such as libraries has for a long time reduced the enrollment population in the Saudi Arabian institutions of higher learning aware of the low numbers of students that transition from high schools to colleges. In this regard, the introduction of the Saudi Digital Library is a positive ideology that opens up room for additional admission of students in the country. Interestingly, the uptake of educational technologies through digital libraries opens up space for e-learning and distant learning programs. With colleges concentrated in urban areas, use of the digital library helps those settled in rural colleges to access educational material at their campuses.

Access to books in the Kingdom of Saudi Arabia was simplified as the students are only required to have a university association to access the academic literature online. Unlike in the past where students were required to access physical libraries that suffered various problems such as and not limited to in- 
adequate resources, the introduction of the Saudi digital library has improved academic performance by students as academic literature is now available to them at any location within the country.

As a matter of fact, bridging the digital gap in the country through the improved technical ability to use information technology tools has further amplified the adoption of the Saudi digital library platform. This implies that a significant portion of the student population can access the digital library with minimal interruptions. Before the documentation of research and actual publishing, researchers spend a considerable amount of material and financial resources to compile their findings. For this reason, the Saudi Digital Library helps in strengthening intellectual property rights for the authors as the compressing the research material into one information management system is advantageous to the authors primarily because they get an opportunity to earn from their collective energies.

Interestingly, the usage of the Saudi Digital Library platform also protects authors from exploitation from substandard publishers that often create room for multiplication of the books for personal gains. For example, it is more likely that a researcher will be propelled to publish his/her research articles on the Saudi Digital platform instead of unpopular publishing institutions for the primary reason of authenticity. Fundamentally, research placed online is likely to be read by more people compared to physical libraries (Aldiab et al., 2017) [7].

\section{5) Positive Impacts: infrastructure and internet users}

With the need to upscale their access to higher learning, the Saudi Arabian government has in the recent past concentrated their financial energies towards incorporating the information communication technology to the education system. To further assist in the roll-out, the government through the relevant ministry has improved internet access to urban and rural households with internet users increasing from 200,000 users to 21.6 million in 2015 according to a survey conducted by the Communications and Information Technology Commission in Saudi Arabia (Aldiab et al., 2017) [7].

Competition from diverse telecommunication service providers has also seen an increment in the number of mobile phone users in the country. In reference to these statistics, the need to introduce a digital platform for learners spread across the country to spearhead an improvement in the quality of research was inevitable. An increasing need for quality education in the oil-rich country was illustrated by the proliferation of students in the institutions of higher learning. The available resources in the universities stored in physical libraries gradually became untenable to the escalating number of students thus creating an opportunity to increase the availability of academic resources on an online platform.

Through an online platform, students would be able to access one book at different locations at the same time compared to the one book at a time for one user model perpetuated by physical libraries. Understandably, use of the online platform in the Arabian country has contributed to the institutions of higher learning concentrating on other institutional-based programs such as improve- 
ment in the quality of faculty members and learning facilities such as a classroom. With a high budgetary allocation associated with the purchase of books, the introduction of the Saudi Digital Library spread infrastructure growth to other areas such as making internet connectivity accessible to other regions that host university campuses (Aldiab et al., 2017) [7].

Statistics indicate that the transition from high school to institutions of higher learning such as universities and colleges in Saudi Arabia was dwindling at alarming levels with approximately 335,250 students from the 491,166 students who completed high school in 2014 transitioning to universities. In this regard, the introduction of the Saudi Digital Library opened up opportunities for e-learning to take place with those students left out upon completion of their high school studies enrolling for e-learning platforms (Aldiab et al., 2017) [7].

Previously, the concentration of institutions' of higher learning in urban areas closed access to education to those living in proximity to the regions. However, uptake of the Saudi Digital Libraries and subsequent introduction of campuses across the country helped promote quality access to education in remote areas and scaling up the quality of life in those regions respectively.

Cognizant of the fact that physical libraries are limited to working hours, the introduction of the digital library in Saudi Arabia has opened more opportunities for the learners and faculty members to access research material limitlessly. This implies that students can access library sessions without time limitations only when they have internet connectivity.

Additionally, the costs of maintaining a digital library are lower in comparison to a physical library that incorporates librarians and associated furniture. In light of this, the Saudi Digital library infrastructural project has significantly helped in the reduction of costs associated with maintenance of the physical library and payment of and for human and materials resources. Furthermore, it has eased the hectic experiences of publishers who spend much money to ship copies across the world.

To this effect, the Saudi Digital Library aims at harnessing the publishers and easing the access to information for researchers and students alike in the country in a timely and efficient manner such that users are at liberty to access recent research. For instance, a person using a physical library may only be programmed to use particular literature in the research process negatively affecting the quality of results.

The environment is a crucial element in the education system. In this regard, the Saudi Digital Library optimizes environmental conservation by simply resulting in paperless research. Unlike the physical library where books are vulnerable to wear and tear, the digital library reduces excessive wastes of resources, therefore, making the environment friendlier. Through the use of the digital library in Saudi Arabia, students get an opportunity to concentrate on school work extensively compared to a time when access to library materials was only in physical libraries. In light of this, the improper use of printing material and waste is minimized. 


\section{6) Negative Impact: cyber security, the elasticity of equipment and ethics}

Increased uptake of information management systems across the world has potentially created a leeway for cybercrime associated with theft of personal data and threats to privacy. Although the Saudi Digital Library is a timely innovation to increase information access in the country, the continued threat of cybercrime waters down the good intentions of the developers. With users of the digital platform required to key in their details, it is likely that the information gathered faces imminent threat of privacy violations. Precisely, digital platforms are operated from one central place commonly known as the server (Al-Arifi et al., 2012) [8].

To this effect, server errors comprise the benefits of the innovation. For example, due to increased use by multiple users across the world, the digital platform is prone to server downgrades that threat the smooth provision of knowledge. This implies that students who comprise the largest number of users of digital libraries may suffer from persistent outages.

Moreover, the use of the Saudi Digital Library also alienates a significant portion of the society that has limited access to digital platforms based on among others access to the internet and the costs therein. According to Al-Arifi et al. (2012) [8], Saudi Arabia is not well positioned to fight against information insecurity potentially because a proportionate number of persons in the country are unaware of proper information security techniques such as and not limited to password security and gadget security.

To this effect, the rollout of the Saudi Digital Library platform is destined to achieve negligible results. Prior to the implementation of the educational technology initiative, the government should have conducted extensive awareness campaigns to ensure that users of the digital library are given the opportunity to learn the basic security practices to secure their information (Al-Arifi et al., 2012) [8].

Furthermore, information technology is growing at an alarming rate. In this regard, the changes experienced in the tech world will trickle down to the Saudi Digital Library such that hardware and software are made obsolete within a very short period. Interestingly, the cost of maintaining an elastic technological innovation is high cognizant of the infrastructure required and monetary allocation. For example, hacking is a constant practice that renders information systems irrelevant to the extent of sourcing for qualified human resource and modern equipment to sustain the information management systems. Additionally, the introduction of the Saudi Digital Library was projected to involve diverse partners such as publishers and the information technology specialists, an initiative that resulted in a huge budgetary allocation. In this respect, it is necessary to acknowledge that the digital library platform requires a significant amount of financial, material and human input.

The tech world is constantly changing to align its products to the desirable modern standards. To this effect, the introduction of the digital platform to access research content is threatened by increased modernization of the software 
and hardware required for the smooth provision of services. In light of this, the Saudi digital library implementation will face challenges associated with the acquisition and maintenance of the equipment. For example, if the digital library is using a software or hardware that is outdated, this leads to decreased service delivery and compromise regarding cyber sustainability (Elaiess, 2016) [9].

Regarding implementation, the digital library will cost the government additional allocations for maintenance and outsourcing of professional service providers should they be unavailable in the domestic human resource market. The constant changes in the usage of modern and standards material are unlikely to equal the training offered to users of the same platform thus ultimately recording incongruent results.

Also, the introduction of the digital library was positioned to increase scholarship in institutions of higher learning. However, due to the increased threat associated with cybercrime, maintenance of a larger pool of academic resources on an online platform is vulnerable to attack. In this regard, the cost involved in the maintenance of the virtual library outpaces the costs associated with physical libraries.

In essence, recovery of lost data requires sufficient human initiative that is inadequate in Saudi Arabia. This implies that the country's ministry of higher education did not place keen attention to the sustainability of the digital library in terms of available information management systems resource pool, therefore, compromising the entire innovation.

As the need for information expands capacitated by the introduction of digital libraries, it is important for organizations to instill the best information security systems in conforming to current, emerging and future demands of a technological society. In light of this, access to library materials unabated leads to increased theft of intellectual property. This means that information systems used in the digital libraries must be secured in mitigation as people could easily download property freely and jeopardize the efforts put in place to compile the research material.

The authorities should tighten penetration of information that may compromise service delivery at the Saudi Digital Library mandated to safeguard cyber security. Additionally, ethics is an important element in the handling of intellectual property. To this effect, the Saudi digital library faces the threat of ethics in the provision of quality research material.

Fundamentally, this implies that the research hub may not be sufficiently equipped to sustain the growing student population across the country. Cognizant of the perception that the country's main language is Arabic, the digital library potentially limits its use to the students with no Arabic language basics thus compromising on the result intended by the innovators of the digital platform.

Nevertheless, the success of the digital library platform is sustained by a good working relationship with content publishers. To this effect, the digital learning 
platform is threatened by the publishers' sustainability of the deal. This implies that upon termination of working engagement with the publishers, the digital platform faces imminent closure or downfall. For this reason, the Saudi digital library platform primary intent was to provide academic literature to students and promote intellectual growth but pegging it on the availability of research material from publishers' waters down its sustainability goals.

In light of this, the platform lacks quality control cognizant of the large chunks of material offered by the publishers. In essence, the large portions of information from the publishers may compromise effective learning process as the organization is scarcely resourced to offer quality control. For example, with a negligible human resource to conduct an effective quality assessment of the material provided; banking on the credibility of the publishers is inadequate to sustain a lifelong initiative as projected by the Saudi digital library.

\section{7) Negative Impact: usability of the interface}

Usability of the digital library requires sufficient training and experience. However, the Saudi Digital Library concept faces sustainability threat cognizant of its usability challenges regarding accessing the interface and locating required resources. According to Alasem (2013) [1], statistics gathered from a study on the usability of the digital interface show that only a handful of users were able to use the interface with efficiency scoring a paltry 9.1 percent.

Overconcentration on the digital library as the primary research avenue is gradually watering down the innovativeness of the Saudi Arabian student population. This is because, through the library platform, students are limited regarding researching their very own ways. For example, science and medical students are in constant need for research thus overreliance on the digital library for research kills their innovative skills. Although the Saudi Digital Library helps in the provision of easy access to research material, unavailable limits in the fields of study work against its sustainability.

Universities are critical institutions in the deployment of digital libraries. To this effect, the user interface of the Saudi Digital Library platform is not user-friendly primarily because it does not provide adequate linkages in the provision of data. This implies that a user is unable to navigate through the platform easily. In a physical library, for instance, users are compelled to search through catalogs on their desired research book or journal, a situation that compounds the search regarding time. In light of this, the Saudi Digital Library lacks the prerequisite navigation tools in modern day websites that link users to different sites (Rocha et al., 2015) [10]. Additionally, the Saudi Digital Library does not address the disability concept that helps in easy access by the disabled population. In essence, a visually impaired person is not incorporated into the ideology behind the conception of the digital library.

Use of the digital library platform risks bandwidth problems thus reducing the usability. In essence, although the digital library has numerous books and journals to access information from, maximization of its use through multiple access points is vulnerable to server problems, therefore, resulting in inaccessibility. 
Maintenance of the server is also a costly initiative that threatens the long-term sustainability of the Saudi Digital Library.

Additionally, the digital library threatens data security cognizant of the premise that the information available on the platform may be used for personal gains without proper accreditation. This implies that another researcher may collect data from a book or journal article without acknowledging the source of information resulting in plagiarism and intellectual property theft.

\section{The Future of Saudi Digital Library Privacy, Security and Reduction of Digital Divide}

To achieve maximum support in the implementation process of the digital library, the government through relevant stakeholders should ensure that all involved participants are consulted widely such that the provision of the online library version reaches out to its intended goals. This includes lowering the internet costs and increasing connectivity. In light of this, the accessibility of the internet has been amplified by an unprecedented increase in the number of internet-enabled devices in the market.

To this end, the innovators associated with the Saudi Digital Library should embark on offering interfaces designed in-line with mobile technology. Fundamentally, a student can access content in the digital library using any device. However, in the wake of heightened cybercrime activities across the globe, the Saudi Digital Library developers need to come up with stringent cybersecurity mechanisms to safeguard not only the publishers content but also the user's data. In as much as the digital platform offers limitless access to subscribers, developers must ensure the safety of information is not compromised through among others use of substandard software or hardware.

With the state of education in the oil-rich country, it is likely that internet connectivity, as well as affordability of the internet-enabled devices, work towards the reduction of the digital divide in the society. This implies that access to the internet and acquisition of internet-enabled devices will shortly become a necessity rather than a luxury in the institutions of higher learning cognizant of the premise that the Saudi Digital Library will alienate physical access to academic content. In a futuristic perspective, the Saudi Digital Library will be need-based in an attempt to ensure that every academic discipline is addressed. This is because the initial data in the digital libraries were subjected to science subjects thus alienating other courses. Precisely, this is ineffective in an ever-dynamic education environment (Calhoun, 2014) [11].

\section{Conclusions}

This literature review has hypothetically illustrated the need for the digital libraries in modern learning environments primarily because of their reach effectiveness in the dwindling physical space available. In essence, the utilization of digital libraries in Saudi Arabia has opened more room for research thus ensur- 
ing that students are properly informed while compiling academic content. However, the Saudi Digital Library should not only bank on publishers for content but also create a concrete database that secures their information and team of researchers to collaborate with the publishers. Interestingly, the digital platform, as highlighted in the literature review, has shown that infrastructural development is necessary for continuous information systems improvement. For instance, due to escalating cases of cybercrime, information systems experts are continuously updating their tools to conform to international standards and safeguard against cyber insecurity.

To this end, the Saudi Digital Library must be aligned in a way that user data are not compromised as well as the research material therein. In an ever-changing education environment, the designers must ensure that content is routinely updated. This literature review also argues the government must address policy issues and legislation to make the digitization of library data a workable solution in the information and knowledge-based society.

In conclusion, the Saudi Digital Library has opened up learning opportunities by increasing access to academic literature, therefore, reducing the cost of accessing education in the oil-rich country aware of the impact of high cost of books in academia.

\section{Conflicts of Interest}

The authors declare no conflicts of interest regarding the publication of this paper.

\section{References}

[1] Alasem, A. (2013) Evaluating the Usability of Saudi Digital Library's Interface. Proceedings of the World Congress on Engineering and Computer Science, San Francisco, 23-25 October 2013, 3-7.

[2] Al Bawaba (2018) "We Must Support Crazy Ideas": Knowledge Summit 2018 Hosts Panel Discussion with Winners of the Mohammed Bin Rashid Al Maktoum Knowledge Award.

http://english.alarabiya.net/en/features/2018/12/05/Saudi-Digital-Library-among-wi nners-of-2018-Knowledge-Award.html

[3] Baker, J. (2011) Arabian Prints: The Saudi Digital Library. https://oeb.global/oeb-insights/arabian-prints-the-saudi-digital-library/

[4] Al-Maini, Y. (2013) Issues in Integrating Information Technology in Learning and Teaching EFL: The Saudi Experience. EuroCall Review, 21, 49-55. https://doi.org/10.4995/eurocall.2013.9790

[5] Simsim, M. (2011) Internet Usage and User Preferences in Saudi Arabia. Journal of King Saud University-Engineering Sciences, 23, 101-107. https://doi.org/10.1016/j.jksues.2011.03.006

[6] Adeyinka, T. and Kwanya, T. (2018) Handbook of Research on Managing Intellectual Property in Digital Libraries. IGI Global, New York.

[7] Aldiab, A., Chowdhury, H., Kootsookos, A. and Alam, F. (2017) Prospects of eLearning in Higher Education Sectors of Saudi Arabia: A Review. Energy Procedia, 
110, 574-580. https://doi.org/10.1016/j.egypro.2017.03.187

[8] AlArifi, A., Tootell, H. and Hyland, P. (2012) Information Security Awareness in Saudi Arabia. CONF-IRM, 57, 1-11.

[9] Elaiess, R. (2016) Use of IT by Special Libraries in the Arab World: An Overview. International Journal of Digital Library Services, 6, 13-23.

[10] Rocha, A., Correia, A., Costanzo, S. and Reis, L. (2015) New Contributons in Information Systems and Technologies. Springer, New York. https://doi.org/10.1007/978-3-319-16486-1

[11] Calhoun, K. (2014) Exploring Digital Libraries: Foundations, Practice and Prospects. Facet, London. 